\title{
Early Prenatal Diagnosis of an Extremely Rare Association of Down Syndrome and Transposition of the Great Vessels
}

\author{
CRISTINA CRENGUTA ALBU1*, DINU-FLORIN ALBU², STEFAN-DIMITRIE ALBU³, ANCA PATRASCU4, ANA-ROXANA MUSAT 5 , \\ ALEXANDRU MARIAN GOGANAU6 \\ 'University of Medicine and Pharmacy Carol Davila, Department of Genetics, 37 Dionisie Lupu Str., 020021, Bucharest, Romania \\ 2University of Medicine and Pharmacy Carol Davila, Department of Obstetrics and Gynecology, 37 Dionisie Lupu Str., 020021, \\ Bucharest, Romania \\ 3University of Medicine and Pharmacy Carol Davila, Faculty of Dental Medicine, 37 Dionisie Lupu Str., 020021, Bucharest, \\ Romania \\ ${ }^{4}$ University of Medicine and Pharmacy of Craiova, Department of Obstetrics and Gynecology, 2 Petru Rares Str., 200349, Craiova, \\ Romania \\ ${ }^{5}$ Genetic Lab, 9 Drossu Nicolae Str., 012071, Bucharest, Romania \\ UUniversity of Medicine and Pharmacy of Craiova, Department of General Surgery, 2 Petru Rares Str., 200349, Craiova, Romania
}

\begin{abstract}
Every year, an estimated 7.9 million infants (6\% of worldwide births) are born with serious birth defects [1]. Congenital cardiovascular defects make up one of the largest groups of severe congenital malformations [2]. The incidence of congenital heart defects in different studies varies from about 4/1,000 to 50/1,000 live births [3]. Congenital heart disease is frequently described in patients with Down syndrome and is the main cause of death in this population during the first two years of life [4]. Trisomy 21 with cardiovascular malformations have a maternal age-adjusted regional prevalence of 4.33/10,000 for the white population and 3.70/10,000 for the nonw hite population [5]. Prenatal diagnosis of congenital heart disease is important for proper perinatal and neonatal management, as congenital cardiac malformations occurs in approximately eight of 1000 live births [6]. We present an extremely rare case of early prenatal diagnosis and management of a fetus with trisomy 21 associated with the transposition of the great vessels, one of the most mysterious congenital cardiac malformations.
\end{abstract}

Keywords: prenatal diagnosis, congenital heart defects, transposition of the great vessels, trisomy 21, ultrasound, genetic conseling.

Down's syndrome is a genetic condition in which a person has 47 chromosomes instead of 46, with an additional replica of chromosome number 21 [7]. Down syndrome, also known as trisomy 21, is the most common genetic disorder in newborns, with a frequency of 1:1000 livebirths [8]. This particular trisomy is frequently associated with a varied combination of morphological and structural birth defects like congenital mental disability, hypotonia, characteristic body features, heart defects, and other systemic congenital malformations [9].

The association between Down syndrome and congenital heart disease has been well established since 1950, when the incidence and the type of congenital heart malformations presentin newborns and infants with Down syndrome was thoroughly described [10].

Annually in the European Union, 36000 children are live born with congenital heart disease and 3000 who are diagnosed with congenital heart disease die as a terminations of pregnancy for fetal anomaly, late fetal death, or early neonatal death [11].

Congenital heart defects reduce survival in Down syndrome patients by $72 \%$ [12]. Some forms of congenital heart disease can potentially be prenatal detected in utero, especially the severe ones with considerable fetal and postnatal morbidity and mortality [13]. So, the prenatal ultrasound screening and genetic testing are absolutely necessary for the early detection of congenital fetal abnormalities [14]. During prenatal ultrasound examinations it is important to examine the fetal face and skull because abnormalities of these structures may indicate the presence of other, more subtle anomalies like congenital heart defects, syndromes, chromosomal abnormalities trisomy 21, or even rarer conditions, such as infections, metabolic disorders [15]. Early prenatal diagnosis and treatment of congenital heart disease is of prime importance to improve the quality of life of children with Down syndrome [12].

The atrioventricular canal is the classic congenital heart anomaly in Down syndrome [16]. The transposition of the great vessels was first described by Mathew Baillie in 1797, in the second edition of the book The Morbid Anatomy of Some of the Most Important Parts of the Human Body [17, 18].

Transposition of the great vessels is a group of congenital cardiac malformations involving an abnormal spatial arrangement of any of the great vessels [19]. The incidence is estimated at 1 in 3,500-5,000 live births, with a male-to-female ratio 1.5 to $3.2: 1$ [18]. In Europe, it is the fourth most common type of major cardiac defect, representing $5 \%$ of all congenital heart disease [ 20 , 21]. Also, transposition of the great vessels is one of the most severe cyanotic heart defect, an one of the most mysterious congenital heart disease, with is still unknown aetiology, very rarely associated with genetic syndromes, such as Turner, Noonan, Williams or Marfan syndromes, and in Down syndrome, it is virtually absent $[18,21]$.

\section{Experimental part}

A 39-years-old, healthy woman, pregnant for the first time comes to our clinic for an ultrasound investigation as part of the routine pregnancy control. 
The current pregnancy is the first pregnancy of a Caucasian couple. The father is a healthy 43 year-old man. There was no consanguinity or relevant family history of congenital birth defects or chromosomal abnormalities.

The ultrasound examination was performed using a GE Voluson E10 Ultrasound System, which highlights a monofetal pregnancy, 22 week of gestation.

The ultrasound examination performed using 2D, 3D and $4 \mathrm{D}$ ultrasound examination techniques, showed lower skull, head biparietal diameter (BPD): $54.4 \mathrm{~mm}$, occipito-frontal head diameter (OFD): $67 \mathrm{~mm}$ and head circumference $(\mathrm{HC}): 191.3 \mathrm{~mm}$. The cerebellum has normal structure and configuration: $26.3 \mathrm{~mm}$, and cerebral hemispheres are symmetrical and have a normal compliance. Blood flow in the middle cerebral artery shows the following values: peak systolic velocity (PSV): 28.08 $\mathrm{cm} / \mathrm{s}$, diastolic velocity (EDV): $5.73 \mathrm{~cm} / \mathrm{s}$, systolic to diastolic (S/D) ratio: 4.9 , pulsatility index $(\mathrm{PI}): 1.49$, resistive index (RI): 0.88 (normal range).

The ultrasound examination of the fetal face showed flat facial features with rounded forehead, upward slanting eyes, small nasal bone lengths: $6.7 \mathrm{~mm}$, micrognathia and retrognathia. Orbital ultrasound biometry showed: inner orbital distance: $13.9 \mathrm{~mm}$ and outer orbital distance: $34 \mathrm{~mm}$ (fig. 1).

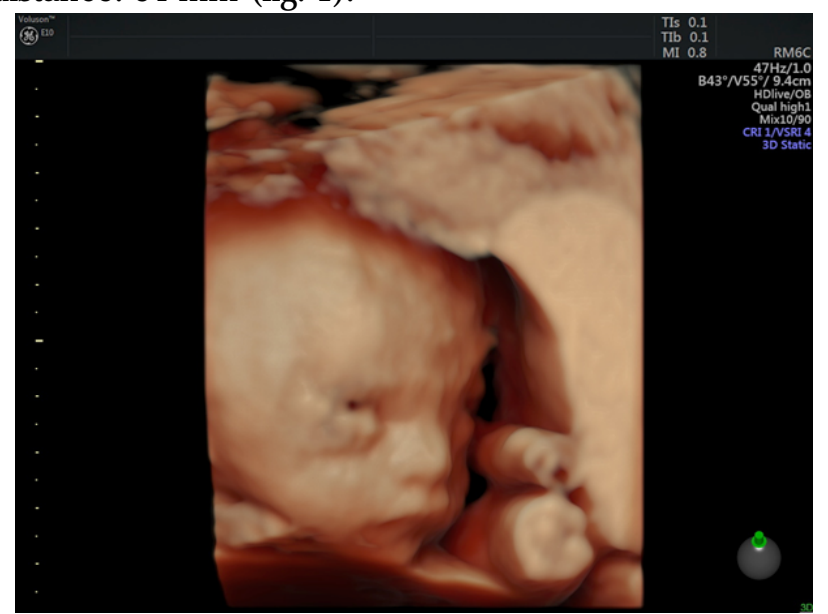

Fig. 1. Ultrasound examination of the fetal face shows flat facial features, upward slanting eyes, small nasal bone lengths, micrognathia and retrognathia.

The neck has a normal configuration, with nuchal translucency (NT) thickness: $3 \mathrm{~mm}$, and the thorax has normal form and structure, with anterior-posterior diameter: $47.9 \mathrm{~mm}$ and transverse diameter: $47.7 \mathrm{~mm}$.

The cardiac screening examination of the fetus showed: horizontal position of the heart with parallel arrangement of the great vessels, atrioventricular canal defect and $3 \mathrm{~mm}$ pericardial effusion (fig. 2-4).

The abdomen is normally configured with anteriorposterior diameter: $48.3 \mathrm{~mm}$, transverse diameter: 52.1 $\mathrm{mm}$ and abdominal circumference: $178.1 \mathrm{~mm}$.

Long-bone ultrasound fetal biometry showed an abnormal dimensions: shorthumeral length $(\mathrm{HL}): 33.4 \mathrm{~mm}$ and short tibia length (TIB): $30.7 \mathrm{~mm}$ (fig. 5). The length of other long bones are: radius: $28.4 \mathrm{~mm}$, ulna: $30 \mathrm{~mm}$, femur: $37 \mathrm{~mm}$ and fibula: $31.2 \mathrm{~mm}$ (normal range).

The umbilical cord is tri-vascular and the umbilical artery blood flow has the following values: peak systolic velocity (PSV): $33.15 \mathrm{~cm} / \mathrm{s}$, diastolic velocity (EDV): 7.71 $\mathrm{cm} / \mathrm{s}$, systolic to diastolic (S/D) ratio: 4.3, pulsatility index (PI): 1.37, resistive index (RI): 0.77 (normal range).

The amniotic fluid volume is in normal quantity and the amniotic fluid index (AFI): $14.2 \mathrm{~cm}$.

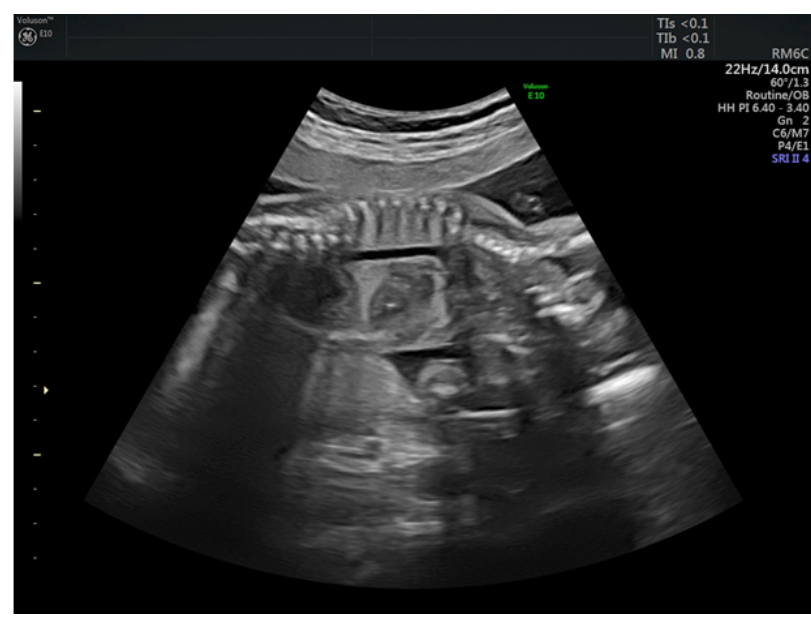

Fig. 2. Fetal echocardiography: The scan shows the spatial arrangement of the aortic arch.

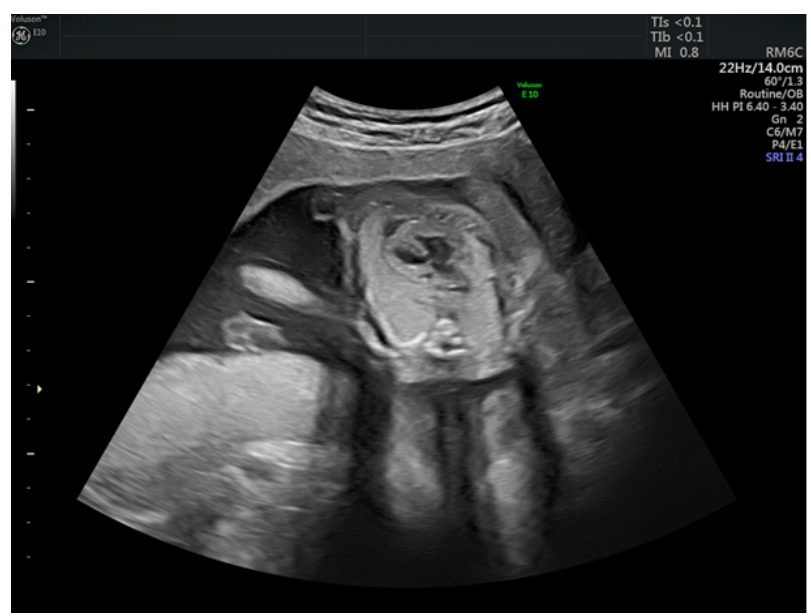

Fig. 3. Fetal echocardiography shows atrioventricular canal defect and $3 \mathrm{~mm}$ pericardial effusion.

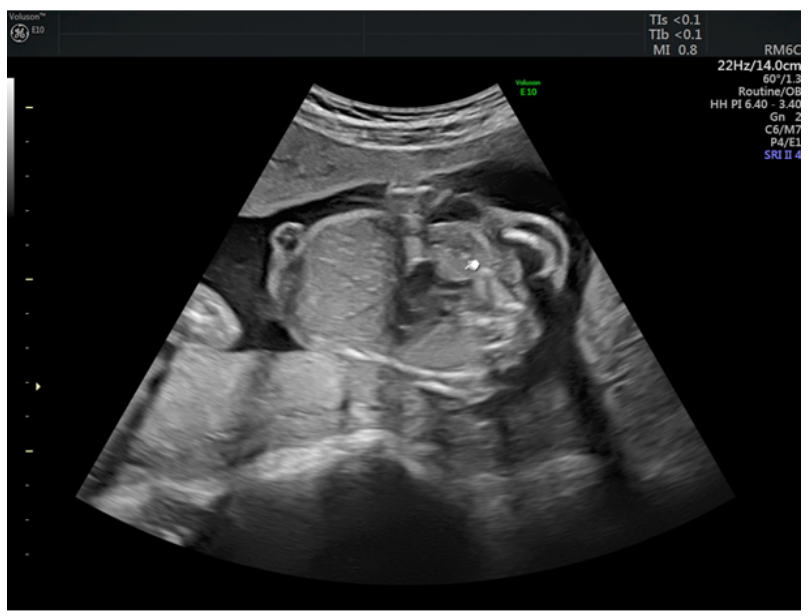

Fig. 4. Fetal echocardiography shows the parallel arrangement of the great vessels.

The placenta is located posteriorly, presents homogeneous structure, degree of maturation 0 and thickness: $30 \mathrm{~mm}$ at the insertion of the umbilical cord.

Predicted fethal hemoglobin based on predicted multiple of the median (MoM) values is $11.2 \mathrm{~g} / \mathrm{dL}$, and estimated weight of fetus: $430 \mathrm{~g}$.

After the ultrasound examination, following a large discussion with a maternal-fetal medicine consultant, it was decided to perform additional specific prenatal genetic investigations, including amniocentesis and fetal karyotype, because the prenatal diagnosis of a major cardiac malformation requires further assessments for extracardiac and chromosomal disorders [13] 


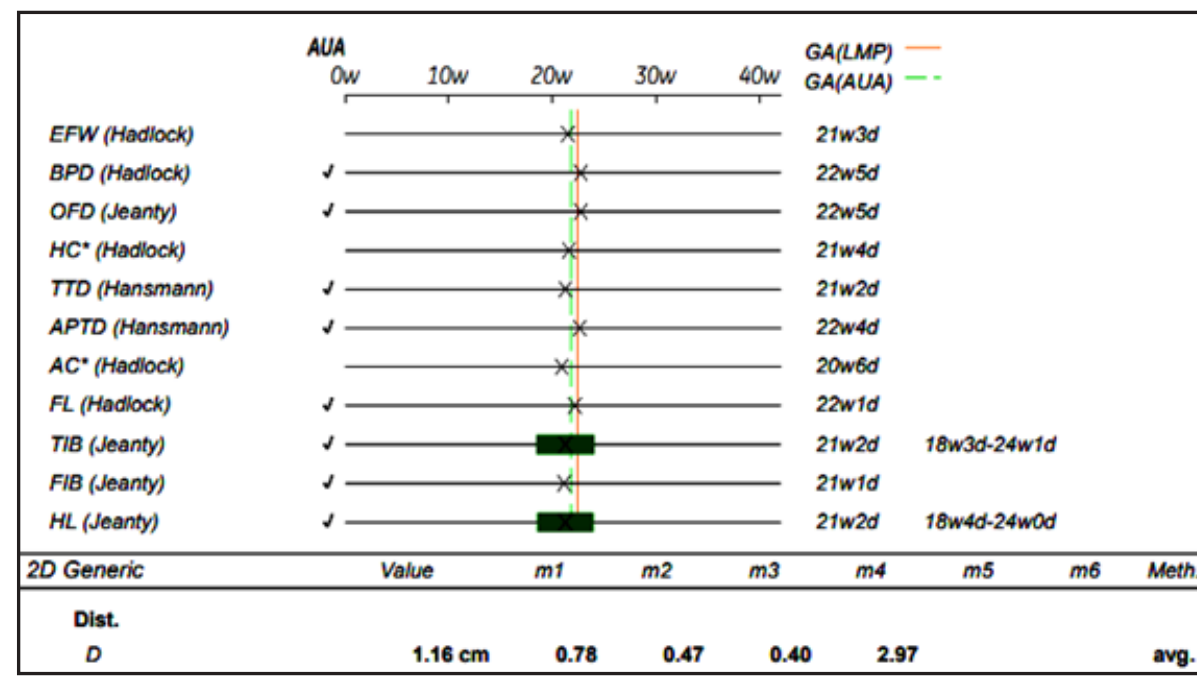

Fig. 5. Results of ultrasound fetal biometry shows skeletal deformity: short length of humerus $(\mathrm{HL})$ and tibia $(\mathrm{TIB})$.
Genetic amniocentesis was done at 22 weeks of pregnancy, to obtain a small amount of clear amniotic fluid, collected using a fine needle.

To reduce parent stress and the time for diagnosis, a sample of amniotic fluid was sent for rapid detection of common chromosomes aneuploidies using Quantitative Fluorescent Polymerase Chain Reaction (QF-PCR) analysis for chromosomes 13, 18, 21, $X$ and $Y$.

Genomic DNA was extracted using a commercial kit (Favorgen, Biotech Corp.).

The rapid detection of trisomies 13, 18, 21 and sex chromosomes aneuploidies was performed by multiplex QF-PCR kit.

For chromosome 21, we analyzed 5 short tandem repeats (STRs) markers: D21S11, D21S1437, D21S1409, D21S1411, and D21S1435 (table 1).

The detection and quantification of the PCR products was performed by capillary electrophoresis (CE), using fluorescence-labeled primers, analyzing the peak height size and peak areas of STR alleles (GeneMapper $\circledast$ ID Software Version 3.2, ABI PRISM ${ }^{\circledR} 310$ Genetic Analyzer*, by Applied Biosystems, CA, USA).
Also, rapid fluorescence in situ hybridization (RapidFISH) on uncultured amniocytes has been performed using commercially available chromosome-specific DNA probes for chromosomes 13, 18, 21, X, Y and traditional metaphase chromosome analysis, obtained from cultured amniocytes.

\section{Results and discussions}

Prenatal ultrasound examination revealed a single live fetus at 22 weeks of gestation with grossly abnormal morphology. The fetus had complex craniofacial abnormalities (abnormal facial profile, small nasal bone, micrognathia and retrognathia), skeletal deformity (short length of humerus and tibia), and extremely rare and importantcardiac malformations: transposition of the great vessels and atrioventricular canal defect.

Prenatal diagnosis of congenital heart disease plays a substantial role in improving the outcome of fetal congenital heart malformations by contributing to optimized perinatal management and providing parents with useful information to make a decision regarding their pregnancy [22].

\begin{tabular}{|c|c|c|l|}
\hline Name & Location & \multicolumn{1}{|c|}{$\begin{array}{l}\text { Allele size } \\
\text { range (bp) }\end{array}$} & \\
\hline D21S11 & $21 \mathrm{q} 21.1$ & $220-283$ & TTTCTCAGTCTCCATAAATATGTG \\
\hline & & & GATGTTGTATTAGTCAATGTTCTC \\
\hline D21S1437 & $21 \mathrm{q} 21.1$ & $283-351$ & 6-F-CTACCACTGATGGACATTTAG \\
\hline & & & GTGGAGGGTGTACCTCCAGAA \\
\hline D21S1409 & $21 \mathrm{q} 21.2$ & $160-220$ & PET-GGAGGGGAATACATTTGTGTA \\
\hline & & & TTGCCTCTGAATATCCCTATC \\
\hline D21S1411 & $21 \mathrm{q} 22.3$ & $256-345$ & ATAGGTAGATACATAAATATGATGA \\
\hline & & & NED- \\
\hline & & & TATTAATGTGTGTCCTTCCAGGC \\
\hline
\end{tabular}

Table 1

DETAILS OF THE MOLECULAR MARKERS: NAME OF THE MARKER, CYTOGENETIC LOCALIZATION, FLUORESCENT LABEL, AND THE RANGE OF THE ALLELE RESULTED FROM THE PCR. 


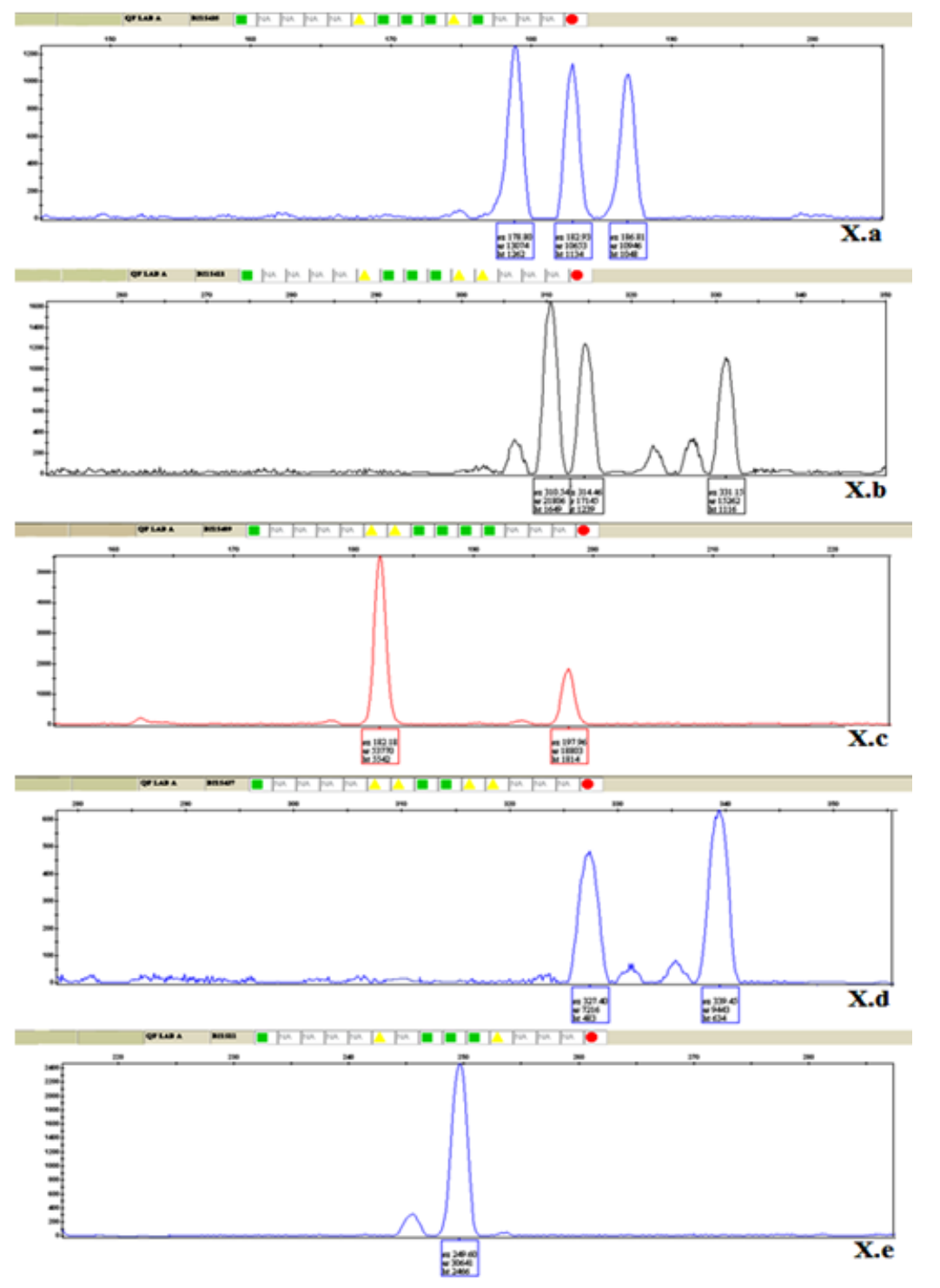

Fig. 6. Electroforegrams of QF-PCR products from a trisomy 21 sample. The $0 X$ axis indicates the size of the fragments (base pair length) and the OY shows the relative fluorescence units. Two short tandem repeat (STR) markers, D21S1411 (X.a) and D21S435 - (X.b), exhibit three peaks with a 1:1:1 ratio. Two peaks with a 2:1 ratio were observed for $D 21 S 409$ (X.C) and two peaks with a 1:2 ratio appear for D21S1437 (X.d). The STR marker D21S11 (X.e) revealed an uninformative QF-PCR product (a single allele).

Fig. 7. Fetal karyotype: $47, X X,+21$ (Slide 1 ) Specimen type: Amniotic fluid, 22 weeks of pregnancy

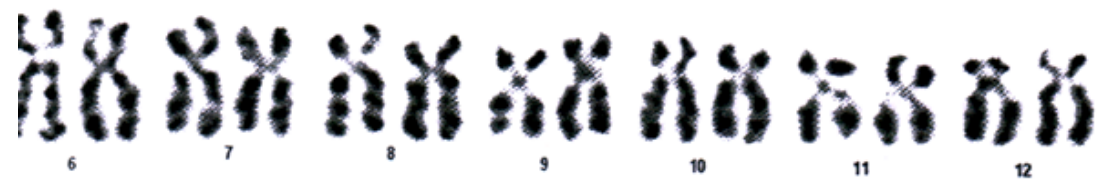

\section{तil

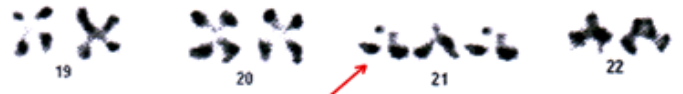 \\ 88}

QF-PCR analysis, a rapid, robust and accurate diagnostic method for detecting common aneuploidies in high-risk pregnancies, with results available in two days because fetal cells do not have to be cultured, indicate the presence of trisomy 21 [23]. The electroforegrams of QF-PCR products from a trisomy 21 sample are presented in figure 6.

From the amniotic fluid sample two integral procedures were performed, and both procedures (fetal DNA extraction, PCR amplification and electrophoretic migration) provided the same result: trisomy 21.

Also, rapid fluorescence in situ hybridization (RapidFISH) performed on uncultured amniocytes, a reliable and fast method for detecting numerical chromosomal aberrations in prenatal diagnosis of chromosomes 13, 18, $21, X, Y$, had revealed trisomy 21 [24] .

Traditional metaphase chromosome analysis, obtained from cultured amniocytes showed a fetal karyotype $47, X X,+21$ and confirm the diagnosis of Down syndrome (fig. 7). 
QF-PCR analysis, FISH testand conventional cytogenetic analysis of cultured amniocytes did not indicate the presence of any aneuploidy of the fetal chromosomes 13, 18 and $X$. The genetic sex of the fetus was feminine.

The traditional gold standard for prenatal diagnosis of chromosome abnormalities is metaphase chromosome analysis through $\mathrm{G}$ banding, because the primary advantages of standard cytogenetic analysis are the ability to detect aneuploidies as well as structural chromosomal aberration with great accuracy [25].

After a multidisciplinary and careful genetic counselling the parents were informed about the genetic condition of Down syndrome and the severity of the associated cardiac malformations of the fetus, and opted, to terminate the pregnancy for medical reasons. The autopsy confirmed the prenatal ultrasound diagnosis.

During the investigations and genetic counselling, the parents were supported by a multidisciplinary team including obstetrician, clinical geneticist, maternal-fetal consultant, paediatric cardiologist and psychologists with great experience in the prenatal testing domain.

Prenatal ultrasound examination was very useful in the detection, management and prognosis of this case, because one of the most importantneonatal morbidity and mortality coordonates is represented by congenital heart malformations, that appear in 40-50\% of the patients with Down syndrome, being an important reference element for the survival rate [26-28].

Type and severity of aneuploidy, type of diagnostic procedure, maternal age, and ethnicity contribute to patients' decision-making in the setting of fetal aneuploidy [29].

\section{Conclusions}

Prenatal ultrasound examination, fetal echocardiography, cytogenetic investigations and molecular genetic analysis play a substantial role in the early prenatal diagnosis, optimized perinatal management and prognosis of the fetus with an extremely rare congenital developmental disorder characterized by transposition of the great vessels and Down syndrome.

\section{References}

1. LOBO, I., ZHAUROVA, K. Nature Education. 1, no 1, 2008, p. 18 2. PRADAT, P., FRANCANNET, C., HARRIS, J.A., ROBERT, E. Pediatr Cardiol. 24, no 3, 2003, p. 195

3. HOFFMAN, J.I., KAPLAN, S. J Am Coll Cardiol. 39, no 12, 2002, p. 1890

4. BENHAOURECH, S., DRIGHIL, A., HAMMIRI, A.E. Cardiovasc J Afr. 27, no 5, 2016, p. 287

5. FERENCZ, C., NEILL, C.A., BOUGHMAN, J .A., RUBIN, J .D., BRENNER, J., PERRY, L.W. J. Pediatr. 114, no 1, 1989, p. 79

6. STRAUSS, A., TOTH, B., SCHWAB, B., FUCHSHUBER, S., SCHULZE, A., NETZ, H., HEPP. H. Eur J Med Res. 6, no 2, 2001, p. 66
7. FULSE, A.C., BASHEER, M.S.M., KSHEERSAGAR, D.D., PAIKRAO, V.M. International J ournal of Anatomy, Radiology and Surgery. 6, no 2, 2017, p. 1

8. WEIJERMAN, M.E., DE WINTER, J.P. Eur J Pediatr. 169, no 12, 2010, p. 1445

9. ELMAGRPY, Z., RAYANI, A., SHAH, A., HABAS, E., ABURAWI, E.H. Cardiovasc J Afr. 22, no 6, 2011, p. 306

10. EVANS, P.R. Br Heart J. 12, no 3, 1950, p. 258

11. DOLK, H., LOANE, M., GARNE, E., EUROPEAN SURVEILLANCE OF CONGENITAL ANOMALIES (EUROCAT) WORKING GROUP. Circulation. 123, no 8, 2011, p. 841

12. DE RUBENS FIGUEROA, J., DEL POZZO MAGANA, B., HACH, J.L.P., J IMENEZ, C.C., URBINA, R.C. Rev Esp Cardiol. 56, no 9, 2003, p. 894

13. FASNACHT, M.S., JAEGGI, E.T. Ther Umsch. 58, no 2, 2001, p. 70 14. ION, G., ALBU, C.C., ALBU, S.D., ALBU, D.F. Ejbps. 4, no 4, 2017, p. 670

15. MAK, A.S.L., LEUNG, K.Y. Ultrasonography. 38, no 1, 2019, p. 13 16. MARINO, B., VAIRO, U., CORNO, A., NAVA, S., GUCCIONE, P., CALABRO, R., MARCELLETTI, C. Am J Dis Child. 144, no 10, 1990, p. 1120

17. BAILLIE, M. CA Cancer J ournal for Clinicians. 24, no 1, 2008, p. 49 18. MARTINS, P., CASTELA, E. OrphanetJ Rare Dis. 3, no. 27, 2008, p.1 19. SEMRAD, M., KRAJ ICEK, M., SEBESTA, P. Cardiovascular Surgery. Karolinum Press, Prague, 2015, p. 268

20. PEXIEDER, T., BLANC, O., PELOUCH, V., OSTADALOVA, I., MILEROVA, M., OSTADAL, B. Late fetal development of retinoic acidinduced transposition of great arteries: morphology, physiology, and biochemistry. In: CLARK, E.B., MARKWALD, R.R., TAKAO, A. Developmental Mechanism of Heart Disease, Futura Publishing, Armonk (NY), 1995, p. 297

21. UNOLT, M., PUTOTTO, C., SILVESTRI, L.M., MARINO, D., SCARABOTTI, A., MASSACCESI, V., CAIARO, A., VERSACCI, P., MARINO, B. Front Pediatr. 1, no 11, 2013, p. 1

22. LIU, X., XU, W., YU, J., SHU, Q. World Jnl Ped Surgery. 2, no 1, 2019. $p 1$

23. DE MORAES, R.W., DE CARVALHO, M.H.B., DE AMORIM-FILHO, A.G., FRANCISCO, R.P.V., ROMAO, R.M., LEVI, J.E., ZUGAIB, M. Clinics. 72, no 7, 2017, p. 400

24. LACZMANSKA, I., STEMBALSKA, A., SLEZAK, R., KOZLOWSKA, J., MAKOWSKA, I., CZEMARMAZOWICZ, H., PESZ, K.A., SMIGIEL, R., JAKIEL, A., SASIADEK, M.M. Ginekol Pol. 78, no 12, 2007, p. 952 25. FAUZDAR, A., CHOWDHRY, M., MAKROO, R.N., MISHRA, M., SRIVASTAVA, P., TYAGI, R., BHADAURIA, P., KAUL, A. Indian J Hum Genet. 19, no 1, 2013, p. 32

26. ALBU, D.F., ALBU, C.C., ALBU, S.D. Int J Med Res Rev. 4, no 1, 2016, p. 118

27. PUIAC, M.A., SUCIU, H., CIORBA, M.I., OPRIS, M.M., AL HUSSEIN, H. , AL HUSSEIN, H., BRINZANIUC, K. Rev.Chim.(Bucharest), 68, no 11, 2017, p. 2658

28. PACURAR, M., DRAGOMIR, B., SZALONTAY, A.S., ROMANEC, C. Rev.Chim.(Bucharest), 69, no 1, 2018, p. 208

29. SHAFFER, B.L., CAUGHEY, A.B., NORTON, M.E. Prenat Diagn. 26, no 8, 2006, p. 667

\footnotetext{
Manuscript received:30.11.2018
} 